\title{
Cuando construir también es pensar: la arquitectura anagógica de Saint Denis
}

\section{Oscar Federico Bauchwitz}

Universidade Federal do Rio Grande do Norte, Brasil

Recibido el 13 de marzo de 2019. Aceptado el 20 de mayo de 2019.

\begin{abstract}
Resumen
Este artículo busca saber en qué medida la iglesia de Saint Denis corresponde a las observaciones heideggerianas acerca del construir y del habitar, evidenciando el vínculo de Suger con las doctrinas de Dionisio, el pseudo-Areopagita, y Juan Escoto Eriúgena desde una perspectiva anagógica de la naturaleza y del mundo.
\end{abstract}

PALABRAS CLAVE: HEIDEGGER, SUGER, SAINT DENIS NEOPLATONISMO, ARQUITECTURA

\section{When Building is also Thinking: the Anagogical Architecture of Saint Denise}

\begin{abstract}
This paper aims to know in what measure the church of Saint Denis corresponds to the Heideggerian observations about the construction and living, evidencing the connection between Suger of Saint Denis and the doctrines of Dionisius Pseudo-Areopagita and John Scottus Eriugena from an anagogical perspective of nature and of the world.
\end{abstract}

KEYWORDS: HEIDEGGER, SUGER, SAINT DENIS, NEOPLATONISM, ARCHITECTURE

El título puede provocar cierta inquietud pues al decir "cuando construir también es pensar", uno puede preguntarse si es posible que existan ciertas construcciones que no pertenezcan al pensar; es decir, ¿entre las incalculables construcciones realizadas por el ser humano a lo largo de su historia, algunas podrían identificarse o pertenecer al pensar, mientras otras, al parecer, estarían desvinculadas de él? Tal inquietud es razonable. Sin embargo, el título no quiere expresar una división o una clasificación en el universo de las cosas construidas. Tampoco se trata de establecer una jerarquía de propósitos sobre lo que se construye. Además, el título se completa diciendo: "la 
arquitectura anagógica de Saint Denis", señalando el caso en que construir también es pensar. Esta determinación no significa que por tratarse de una construcción de carácter religioso se evidenciaría cierta elevación espiritual y de un pensar más abstracto, mientras otras construcciones están destinadas a actividades más necesarias y apremiantes. La inquietud no hace más que agravarse porque, considerando obras tan funcionales como un centro comercial o un aeropuerto, una hidroeléctrica o una carretera, ¿quién podría negar que haya sido la capacidad de pensar la que logró establecer sus respectivas funcionalidades y garantizar la seguridad que tales obras requieren?

En la conferencia "Construir, Habitar, Pensar" (1951), pronunciada en Darmstadt en ocasión del congreso El hombre yel espacio, Heidegger postulaba que el ser humano construye porque habita y no que habita porque construye. Una cosa es decir, por ejemplo, que el profesor y sus alumnos se reúnen en determinada aula de una universidad porque esta aula fue construida según las reglas de la construcción, imaginada por arquitectos, calculada por ingenieros y laboriosamente levantada por albañiles. A su vez, esta aula participa del todo y atiende a la funcionalidad que se espera de un edificio universitario. Una universidad, con sus numerosas salas y laboratorios, se destina a la generación y transmisión de conocimientos y, quizá, puede llegar a promover la experiencia del pensamiento filosófico. La reunión de profesor y alumnos hace que el aula sea lo que es; al reunirse en ella, habitan lo que un día se construyó. Todo esto es muy fácil de ser comprobado y nadie podría negar tales hechos. Sin embargo, el lenguaje parece indicar algo más que una relación causal entre el construir y el habitar. El hecho de que el ser humano construya su mundo, en el cual tiene lugar la universidad y una de sus aulas, tiene origen en algo propio del modo de existir del ser humano. Dicho de otro modo: ¡construimos porque ya habitamos! Y no al revés, diría Heidegger.

En el contexto histórico al cual pertenece la conferencia heideggeriana, tiempos de posguerra presionados por los desafíos de la reconstrucción de Europa, las cuestiones planteadas por Heidegger pueden haber parecido "cosas de filósofos", es decir, elucubraciones que no guardan un compromiso con la realidad o que no comportan un programa mínimamente pragmático y, por lo tanto, un discurso no apto para colaborar efectivamente con los problemas de aquella época y aún de hoy.

Heidegger recuerda que, al terminar la lectura de "Construir, Habitar, Pensar", sufrió violentos ataques: lo acusaban de destruir y menospreciar las cuestiones que se planteaban en el congreso y que movilizaban a todos los allí reunidos (cf. 2014: 89 y 1983: 127 ss.). De hecho, ya al comienzo de su conferencia, Heidegger advierte que no tiene "la pretensión de encontrar ideas sobre la construcción, ni menos dar reglas sobre cómo construir" (1994: 127). Más que nada, lo que se desarrolla a partir de esta advertencia es un intento de responder dos cuestiones fundamentales para el rumbo de texto: ¿qué es habitar? y ¿en qué medida pertenece al habitar un construir? Es como resonancia de las cuestiones planteadas por Heidegger que el título "cuando construir también es pensar" propone pensar un ejemplo de construcción que corresponde a la reflexión heideggeriana, al tiempo que expresa un aspecto fundamental del pensamiento neoplatónico: una visión anagógica de la naturaleza y del mundo que propició un modo de construir, una arquitectura anagógica.

La idea de que la iglesia abacial de Saint Denis pueda ser vista como el marco inicial de un determinado modo de construir es algo admitido por los estudiosos de la historia del arte y, especialmente, de la arquitectura. Se acepta que, con Saint Denis, gracias a las reformas de ampliación e innovaciones técnicas realizadas por su abad y arquitecto a mediados del siglo XII se inaugura el tiempo del gótico. Las características de lo que vino a ser llamado "gótico" fueron aplicadas, perfeccionadas, llevadas a dimensiones nunca vistas y se multiplicaron por toda Europa. 
Las transformaciones llevadas a cabo en Saint Denis y el ingenio de su abad tienen su lugar en la historia de la arquitectura, pero también se pueden situar en el influjo de la tradición neoplatónica medieval y del apofatismo cuando se considera la recepción que alcanza la noción de anagogía presente en el pseudo-Areopagita y en Eriúgena en la obra de Suger de Saint Denis. Simson, en su La iglesia gótica, sostiene que "en el caso de este monumento [sc. la iglesia de Saint Denis] puede demostrarse cómo un sistema metafísico concreto inspiró el diseño artístico, de qué modo una experiencia intelectual informó el proceso creativo que tiene lugar en la mente del artista" (1980: 119). ${ }^{1}$ También Beierwaltes considera que Saint Denis ilustra a la perfección de qué modo "una idea implícitamente filosófica y pronunciadamente teológica determina fundamentalmente la arquitectura en su configuración formal" (2009: 111). Saint Denis permitiría una experiencia directa de aquello que la doctrina de la teofanía sostiene, una comprensión del mundo como metáfora, una interpretación que lejos de condenar, resguarda el mundo material como puerta de acceso a lo inmaterial. Tal es el sentido de la anagogía que Suger encuentra en la obra dionisiana y en su comentador: una perspectiva metafórica que conduce el pensamiento a ir más allá de sí mismo.

Panofsky observa que el abad de Saint Denis descubre, en las traducciones de la obra dionisiana y en los comentarios compuestos por el Irlandés, "no sólo el arma más poderosa contra San Bernardo, sino también una justificación filosófica de toda su actitud hacia el arte y la vida" (2004: 34$).^{2}$ Y, efectivamente, uno puede encontrar en las obras del pseudo-Areopagita y de Eriúgena una concepción del mundo que lejos de infravalorar su forma de ser -es decir, su consistencia material- fundamenta sobre él y sobre sus diferencias la propia posibilidad de una visión de Dios, la teofanía. Esta perspectiva "teofanista" constituye una réplica a quienes critican los excesivos gastos materiales y espirituales demandados por la reforma de Saint Denis. Con estos precursores, Suger "en vez de volver la espalda al mundo físico, puede tener la esperanza de transcenderlo absorbiéndolo" (Panofsky, 2004: 35). Veamos ahora la descripción que hace Suger de la experiencia suscitada por su iglesia:

de vez en cuando la belleza de la casa del señor o el esplendor multicolor de las piedras preciosas me alejan, por el placer que producen, de mis propias preocupaciones, y cuando la digna meditación me invita a reflexionar sobre la diversidad de las santas virtudes, trasladándome de las cosas materiales a las inmateriales (de materialibus ad immaterialia transferendo), siento habitar (demorari) en una extraña región del orbe terrestre (extranea orbis terrarum plaga), que no llega a estar por completo en la faz de la tierra ni en la pureza del cielo, y que, por la gracia de dios, puedo trasladarme de un lugar inferior hacia otro superior de un modo anagógico (anagogico more). ${ }^{3}$

La anagogía es el método de Suger y un modo de abrir lugares. Con ella, la interpretación va más allá del razonamiento que, paradójicamente, permitió y erigió Saint Denis, es decir, las técnicas del construir corresponden y materializan un pensamiento anagógico por el cual lo visible da paso a lo invisible. La anagogía es la búsqueda y la construcción de un lugar - "una extraña región"- que permite el encuentro de tierra y cielo. Ese encuentro emerge del movimiento de "traslado" (transferendo) de una a otra dimensión, la material y la inmaterial, conduciendo al observador a las cosas inmateriales desde las materiales, de lo inferior a lo superior. En ese lugar propiciado por la anagogía, como describe Suger, uno puede "experimentar la permanencia" (demorari) en esa región abierta, un espacio logrado, un lugar donde se experimenta

1 Para Simson, "es aún más curioso pensar que sin las falsificadas credenciales de un anónimo escritor sirio que vivió seiscientos años antes, la arquitectura gótica podría no haber nacido nunca" (1980: 122).

2 Para las críticas de San Bernardo de Claraval a la ostentación de Saint Denis, véase Panofsky, 2004: 34.

3 Sugerii abbatis sancti dionysii liber, De rebus in administratione sua gestis - Suger, abad de Saint Denis, "De las obras realizadas durante su administración", trad. en Panofsky, 2004: 81. 
la propia apertura como una posibilidad superior porque libre: un modo extraordinario de habitar y de construir lugares en el mundo que abriguen y dejen ver esa inadvertida posibilidad de ver lo oculto, que conquiste la plasticidad de lo invisible. Como entiende Afonso, el templo religioso deviene el claro donde la divinidad se manifiesta (cf. 2010: 80).

El influjo de la obra dionisiana es determinante en la concepción artística de Suger. Para Ulloa, tal influjo posee dos aspectos fundamentales presentes en la construcción: el método anagógico y la teología de la luz, incorporadas en la concepción del chevet (cabecera) con vitrales y "ventanas anagógicas" en el pórtico central y, de un modo general, en los dispositivos técnicos que caracterizarían toda la trayectoria gótica (cf. 2015: 130). La concepción de Suger cobija la enseñanza del pseudo-Areopagita que en su Jerarquía Celeste escribe:

En cuanto nos sea posible estudiemos las jerarquías de los espíritus celestes conforme la sagrada escritura nos lo ha revelado de modo simbólico y anagógico. Centremos fijamente la mirada inmaterial del entendimiento en la luz desbordante más que fundamental, que se origina en el padre, fuente de divinidad (121AB).

Y a continuación:

Nosotros, los hombres, no podríamos de modo alguno elevarnos por una vía puramente espiritual a imitar y contemplar las jerarquías celestes sin ayuda de medios materiales, que nos guíen como requiere nuestra naturaleza. Cualquier persona reflexionando percibe que la hermosura aparente es signo de misterios sublimes (121CD).

En Dionisio, Suger encontrará elementos para justificarse, sea para defenderse de sus detractores, sea para descubrirse a sí mismo como partícipe de una tradición a la cual aportará su contribución: nada menos que la transformación del paisaje europeo. La justificación (incluso moral) de los "medios materiales", la adopción de un método interpretativo volcado a lo misterioso - al tiempo que a la luz- evidencian la mutua pertenencia entre un pensamiento plasmado por el método anagógico y un modo de concebir y construir lugares que correspondan a tal pensamiento.

$\mathrm{Al}$ comentar el pasaje supra citado de la obra dionisiana (Expositiones in Ierarchiam Coelestem), Eriúgena postula: "Las luces materiales, tanto las que están colocadas por la naturaleza en los espacios del cielo como las que son producidas por el artificio humano, son imágenes de las luces inteligibles y sobre todo de la luz verdadera misma" (Exp. 139D: 15.534-538). ${ }^{4}$ El pasaje es esclarecedor. No sólo la creación divina es propiamente teofanía, es decir, Dios manifestándose a sí mismo en cada una de sus creaturas, sino que también aquello que es el producto de la creación humana se reconoce como teofanía. Por medio de su construir, el arquitecto pone luz sobre la propia luz que ilumina a todas las luces. Al conceder una posibilidad concreta de abrigar y de hacer ver la "luz verdadera", la acción humana se reconoce como destinada a ser ella misma una creación extraordinaria.

La doctrina de la teofanía desarrollada por Eriúgena pone en marcha una reflexión sobre el lugar del ser humano en el centro de la creación. Esa reflexión tiene su origen en la diferencia fundamental entre quae sunt et quae non sunt, expresión conceptual de la naturaleza, el comienzo desde donde arranca el pensamiento de Eriúgena sobre la división de la naturaleza. Y esto es así no porque sea anunciada en las primeras líneas de su Periphyseon (la obra magna de Eriúgena luego condenada), sino porque es la diferencia misma la que constituye la existencia. Posee una especie de doble 
primado metafísico -ontológico y me-ontológico-, un comienzo decisivo para pensar qué significa que algo sea y cómo este "ser" guarda correspondencia con algo que no es. La diferencia expone el vínculo entre lo que es y lo que no es; justamente eso es lo que quiere decir physis o natura. Sólo porque hay diferencia es posible pensar que toda experiencia humana consiste en dar lugar a una región muy particular y exclusivamente suya, dónde se advierte y se cobija el hecho evidente, y no menos misterioso, de que

\footnotetext{
todo lo que se comprende y se percibe no es otra cosa sino la aparición de lo no aparente, la manifestación de lo oculto, la afirmación de lo negado, la comprensión de lo incomprensible, clamor del silencio, acceso de lo inaccesible, cuerpo de lo sin cuerpo, la esencia de lo superesencial, la forma de lo sin forma, la medida de lo inmensurable, el número de lo innumerable, el peso de lo que no tiene peso, la materialización de lo espiritual, la visibilidad de lo invisible, el lugar de lo que no tiene lugar, etc. (Eriúgena, Per. III, 633BC: 22.589-595).
}

En este conocido pasaje, pieza central de su doctrina de la teofanía, no es difícil reconocer la existencia de una temática que dice que el ser humano -y su irrevocable vocación de dar lugar al mundo- es la officina omnium (cf. Eriúgena, Per. II, 530D: 10.91), el tercius mundus (cf. Idem, VSp. XIX, 294A: 35.12), reunión de lo sensible y de lo inteligible. Por lo tanto, construir es ya una forma de comprensión y de estar en un mundo que se constituye como modo de realización humana. El ser humano da lugar a las cosas. Dar forma y materialidad, peso y número, visibilidad y cuerpo es ya un modo de construir y de propiciar acceso a lugares que conducen a la visión de lo invisible, como si allí se pudiera habitar un límite indeleble que, de modo extraordinario, parece coincidir con la existencia humana.

La iglesia abacial de Saint Denis ha sufrido transformaciones e innovaciones que le han concedido un aire, sino de prototipo, al menos de un manifestum. De hecho, si uno se propone imaginar una iglesia gótica, necesariamente se encontrará con elementos arquitectónicos presentes en Saint Denis (columnas monolíticas en délit, bóvedas de crucería, ojivas, contrafuertes, arcos rampantes, vitrales, rosáceas, etc.). Todos estos elementos pertenecen al arte del construir y corresponden a una concepción creativa desde un punto de vista técnico. Así es. Sin embargo, podríamos preguntarnos: jes correcto afirmar que lo "gótico" se abre como posibilidad del construir porque dispone de estos artificios, o estos artificios fueron producidos, o mejor, requeridos por un, digamos, modo de ver las cosas? ¿Saint Denis sólo es posible porque dispone de los elementos que le permitieron su verticalidad y sus muros diáfanos o es posible porque, antes de tales elementos, hay un habitar que construye según un pensamiento a partir del cual el hombre puede entenderse a sí mismo y su mundo, a Dios y al modo de relacionarse con él?

Si volvemos ahora la mirada al pensamiento de Heidegger y a su peculiar modo de comprender la relación del pensamiento con el construir, debemos admitir la posibilidad de que el ser humano, más allá del afán de asegurarse un mundo donde habitar, pueda llegar a construir y edificar lugares que permitan la experiencia del habitar desde lo que es propiamente humano. Ir más allá de las apremiantes necesidades cotidianas que asolan al ser humano significa la apertura de lugares libres de cualquier coerción. A tal apertura Heidegger la denominó "topología del ser" (1968: 47), la tarea asignada a ese pensamiento libre y capaz de dejar ver y de dar localidad al ser.

Heidegger no dedicó ninguna reflexión explícita a la arquitectura. Su conferencia en Darmstadt no buscaba prescribir normas o reglas sobre el arte de construir, sino proponer un análisis existencial-ontológico del habitar y del construir, evidenciando 
el modo de ese ente que habita, porque piensa, y que se ve destinado a construir y apropiarse de su mundo. De ese modo, pensando y construyendo, habita el humano sobre la tierra, bajo el sol; se entiende como mortal y en cuanto tal se mide a los divinos. Desde la unidad de estos cuatro: tierra, cielo, mortales y divinos, el habitar acaece un mundo. La ocurrencia del mundo es lo que afianza la existencia humana. Cuando analiza una cabaña de la selva negra o un puente, Heidegger descubre el sentido fundamental del construir como la apertura de lugares. La apertura y su permanencia. Entonces, cuando pensamos en una topología del ser, el análisis de la arquitectura como arte del construir no debería limitarse a examinar las soluciones e innovaciones que una escuela o una corriente arquitectónica propone, sino más bien, qué lugar se procura abrigar y en qué medida ha requerido esas soluciones. O sea, es necesario reconocer la anterioridad ontológica del habitar frente al construir. Reconocer y propiciar lugares que permitan un tal reconocimiento. Para ello, el construir debe poder edificar un mundo lo suficientemente apto para atender a las necesidades humanas, pero también debe ser capaz de albergar un lugar en el cual se da la experiencia de algo que propiamente no es conocido como un ente entre otros, sino que se distingue de todo siendo él mismo un no ente.

A partir de la perspectiva heideggeriana, podemos aceptar que Saint Denis, al tiempo que emerge de un pensamiento pautado fundamentalmente por la metafísica neoplatónica cristiana, también corresponde a su topología. A la vez que este pensamiento se concretizó materialmente, Saint Denis permanece como signo de un habitar y de construir. Los innovadores dispositivos técnicos reunidos en Saint Denis han permitido instaurar un lugar propio guiado por las consignas de la metafísica neoplatónica y su consecuente modo anagógico de entender la realidad. Según este modo se instaura un lugar donde lo material y visible deja ver lo inmaterial e invisible. Para tal instauración, desde la perspectiva abierta por la anagogía, los dispositivos instalados en Saint Denis son fundamentales. Con y por ellos, el lugar que se abre en Saint Denis es lo que es. Los muros traslúcidos con sus vitrales, su rosácea frontal, más allá de expresar una hermenéutica bíblica sirven de emblema metafísico de un lugar y justifican su construcción como una especie de umbral y reunión entre el exterior y el interior del edificio, la "extraña región" experimentada por Suger, la sensación de ser conducido a un lugar totalmente otro frente a las necesidades cotidianas que determinan el mundo. Un lugar descubierto por la perspectiva teofanista y anagógica que construye en función -si es que podemos decirlo así- de algo inusual, la experiencia fundamental sobre el propio construir y el modo de habitar humanos. En Saint Denis toma cuerpo la posibilidad anunciada por el Areopagita y Eriúgena de pensar el mundo como manifestación divina y el protagonismo del ser humano para ejercitarse en esa posibilidad. Una arquitectura anagógica como la que manifiesta Saint Denis es una posibilidad que, aún hoy en día, a nosotros, habitantes de un mundo forjado con vistas a los útiles, nos concede una mirada que cobija lo extraordinario. 


\section{Bibliografía}

\section{Fuentes}

\section{Ediciones}

» Heidegger, M. (1983). "Begegnungenmit Ortega y Gasset". En: Aus der Erfahrung des Denkens 1910-1976. Frankfurt: Vittorio Klostermann. (GA 13).

"Heidegger, M. (2000). "Bauen, Wohnen, Denken”. En: Vorträge und Aufsätze. Frankfurt: Vittorio Klostermann. (GA 7).

» Iohannes Scotus Eriugena (1975). Expositiones in hierarchiam coelestem. Ed. Barbet, J. Turnhout: Brepols. (CCCM 31).

» Iohannes Scotus Eriugena (1997). Periphyseon II. Ed. Jeauneau, E. Turnhout: Brepols. (CCCM 162).

» Iohannes Scotus Eriugena (1999). Periphyseon III. Ed. Jeauneau, E. Turnhout: Brepols. (CCCM 163).

"Iohannes Scotus Eriugena (2008). Homilia et commentarius in evangelium Iohannis. Ed. Jeauneau, E. Turnhout: Brepols. (CCCM 166).

\section{Traducciones}

" Dionisio Areopagita (1990). "La Jerarquía Celeste". En: Obras Completas del Pseudo Dionisio Areopagita. Trad. Martín, T. H. Madrid: BAC.

» Heidegger, M. (1968). Da experiência do pensar. Trad. Tavares de Miranda, M. C. Porto Alegre: Globo.

" Heidegger, M. (1994). “Construir, Habitar, Pensar". En: Conferencias y artículos. Trad. Barjau, E. Barcelona: Ediciones del Serbal, 127-142. (Odós 5).

» Heidegger, M. (2014). "Encuentros con Ortega y Gasset". En: Experiencias del pensar (1910-1976). Trad. de Lara López, F. Madrid: Abada Editores, 89-91.

\section{Bibliografía complementaria}

"Afonso, F. (2010). “O abade Suger e a visão do gótico", Revista de Teologia e Ciências da Religião da Unicap 9.1,73-84.

» Beierwaltes, W. (2009). Eriúgena. Rasgos fundamentales de su pensamiento. Pamplona: EUNSA.

»Panofsky, E. (2004). El abad Suger. Sobre la abadía de Saint-Denis y sus tesoros artísticos. Madrid: Cátedra.

"Simson, O. V. (1980). La catedral gótica. Los orígenes de la arquitectura gótica y el concepto medieval de orden. Madrid: Alianza Editorial.

»Ulloa Molina, E. M. (2015). “De materialibus ad inmaterialia transferendo. El influjo de la filosofía del Pseudo Dionisio Areopagita en la reforma arquitectónica de la Iglesia de la abadía Real de Saint Denis en la época del abad Suger", Revista de Filosofía de la Universidad de Costa Rica 54. Extra 139, 5-225. 


\section{Oscar Federico Bauchwitz}

Profesor Titular UFRN. Bolsista do Programa Institucional de Internacionalização (PRINT) de la Fundación Coordenação de Aperfeiçoamento de Pessoal de Nível Superior (CAPES), en la modalidad de Professor Visitante no Exterior Sênior, Universidad de Sevilla, España (nº: 88887.341794/2019-00). 